\title{
THE LEGEND OF CREATIVE LEARNING: PROPOSIÇÃO DE UM JOGO DE RPG PARA INCENTIVAR A APRENDIZAGEM CRIATIVA
}

\section{The Legend of Creative Learning: Proposition of a RPG game to Encourage the Creative Learning}

Luciano da Silva Rodrigues*

Greyce da Silva Rodrigues**

Silvia de Castro Bertagnolli ${ }^{* * *}$

Marcelo Augusto Rauh Schmitt****

Josiane Carolina Soares Ramos Procasko******

\begin{abstract}
Resumo: Este artigo tem como objetivo apresentar um modelo de jogo de RPG educacional chamado The Legend of Creative Learning, que foi utilizado como estratégia pedagógica para fomentar a aprendizagem criativa na sala de aula. Para tal, são apresentadas as bases teóricas do trabalho referentes às temáticas do presente estudo. O delineamento metodológico é de caráter qualitativo apoiado nos procedimentos de pesquisa bibliográfica e pesquisa-ação para compreensão dos fatos vivenciados. A partir dos estudos teóricos realizados, foi desenvolvido um modelo de jogo de RPG, o qual encontra-se disponível para a utilização em sala de aula. A coleta de dados foi realizada através das produções textuais construídas durante a prática pedagógica com os estudantes, bem como pelo questionário avaliativo respondido por eles. Os resultados desta investigação apontam que a forma de abordar os conteúdos programáticos através do jogo podem aumentar as chances de engajar os alunos, pois utilizam o lúdico para favorecer a aprendizagem e desenvolver a criatividade.
\end{abstract}

\footnotetext{
* Mestrando do Mestrado Profissional em Informática na Educação do Instituto Federal de Educação, Ciência e Tecnologia do Rio Grande do Sul (IFRS). Especialista em Educação a Distância da Universidade do Norte do Paraná (UNOPAR). E-mail: lucianodsradm@gmail.com. Orcid: https://orcid.org/0000-0001-8332-6783.

** Mestranda do Mestrado Profissional em Informática na Educação do Instituto Federal de Educação, Ciência e Tecnologia do Rio Grande do Sul (IFRS). Especialista em Psicomotricidade do Centro Universitário Barão de Mauá (CBM). E-mail: greyceg1 @ bol.com.br. Orcid: https://orcid.org/0000-0003-0403-186X.

*** Doutora em Computação pela Universidade Federal do Rio Grande do Sul (2004). Professora Orientadora Mestrado Profissional em Informática na Educação. Instituto Federal de Educação, Ciência e Tecnologia do Rio Grande do Sul - Campus Porto Alegre - RS / Brasil. E-mail: silvia.bertagnolli@poa.ifrs.edu.br. Orcid: https://orcid.org/0000-0001-7495-6636.

***** Doutor em Informática na Educação. Professor do Mestrado Profissional em Informática na Educação do Instituto Federal de Educação, Ciência e Tecnologia do Rio Grande do Sul - Campus Porto Alegre - RS / Brasil. E-mail: marcelo.schmitt@poa.ifrs.edu.br. Orcid: https://orcid.org/0000-0003-1290-5029.
}

****** Doutora em Educação (UFRGS). Professora do Mestrado Profissional em Informática na Educação. Instituto Federal de Educação, Ciência e Tecnologia do Rio Grande do Sul (IFRS). E-mail: josiane.ramos@ poa.ifrs.edu.br. Orcid: https://orcid.org/0000-0001-7223-6889. 
Palavras-chave: Formação de professores. Role Playing Game (RPG). Tecnologias Digitais (TDs).

\begin{abstract}
This paper presents an educational RPG game model called "The Legend of Creative Learning", to be used as a pedagogical strategy to encourage the creative learning in the classroom. To this end, we present theoretical bases of the work related to the themes of the present study. The methodological approach is qualitative and it is supported in the literature and action research procedures for understanding the experienced facts. As from the theoretical studies, we developed a RPG game model, which is available to students use. The data was obtained through textual productions built during the pedagogical practice with the students, as well as through the evaluation questionnaire answered by them. The results of this investigation indicate that the way to approach the programmatic contents through the game increases the chances of engaging the students, because it uses the ludic to favor the learning and to develop the creativity.
\end{abstract}

Keywords: Teacher training. Role Playing Game (RPG). Digital Technologies (TDs).

\title{
1 Introdução
}

A sociedade moderna está cada dia mais tecnológica e, consequentemente, a sala de aula acaba transformando-se em um espaço no qual as tecnologias começam a ser utilizadas nos processos de ensino-aprendizagem. Várias tecnologias têm sido adotadas por docentes com o intuito de favorecer a aprendizagem dos estudantes. Aplicativos com propósitos educacionais, objetos de aprendizagem, redes sociais, jogos digitais ou de tabuleiro são exemplos.

O uso de jogos educacionais está crescendo nos últimos anos pois, conforme argumentam Sobreira, Viveiro e Abreu (2020), eles "despertam o interesse dos alunos", bem como motivam a aprendizagem (KELLER, 2009). Já Murcia (2005) argumenta que, além de favorecer o engajamento, o uso de jogos em sala de aula é uma atividade lúdica que permite o desenvolvimento da aprendizagem, da personalidade e da inteligência emocional dos estudantes.

Em análise da literatura da área de jogos, constatou-se que existem inúmeros gêneros que podem ser utilizados para desenvolver um jogo que será aplicado em sala de aula: jogos de ação, tiro, corrida, luta, aventura, ação-aventura, simulação, estratégia, RPG (Role Playing Games), dentre outros (SCHUYTEMA, 2008; NOVAK, 2010). Conforme argumentam Bittencourt e Giraffa (2003a), os jogos de RPG trazem importante contribuição: "Dentre as modalidades de jogos utilizados para fins educacionais encontram-se os RPG (Role Playing Games). Os RPG são jogos cooperativos de representação de papéis." (2003b, p. 664). Assim, proporcionam o aprimoramento de habilidades de imaginação, criatividade, empatia, através da construção coletiva de narrativas lúdicas.

Embora o uso de jogos incentive a constituição de um espaço mais dinâmico e, em alguns casos, mais reflexivo, é a intencionalidade pedagógica do professor que conduz as experiências de aprendizagem dos estudantes (SOBREIRA, VIVEIRO, ABREU, 2020). Assim, esta pesquisa-ação foi conduzida de modo a atender os seguintes objetivos: aplicar os conhecimentos prévios sobre teorias da aprendizagem; desenvolver estratégias em equipe; utilizar TDICs (Tecnologias Digitais da Informação e Comunicação) no desenvolvimento de narrativas criativas; e selecionar dados e informações de fontes confiáveis. Para atender a esses 
objetivos, considerou-se que um jogo do gênero RPG seria o mais adequado, pois a estratégia pedagógica exigiria dos estudantes (ou grupo de estudantes) a interpretação de papéis.

Assim, o foco principal deste artigo é apresentar o modelo de jogo de RPG educacional chamado The Legend of Creative Learning, que foi utilizado como estratégia pedagógica para fomentar a aprendizagem criativa na sala de aula. A partir das regras, este jogo foi elaborado para ser uma ferramenta pedagógica de uso livre e gratuito que está organizado em quatro dimensões de interação: trama, cenas, arquétipos e bancos de ideias. O seu principal diferencial é a personalização da temática, ou seja, o tema a ser abordado por ele pode ser customizado de acordo com o conteúdo desejado pelo professor.

O jogo educacional aplicado é norteado pelos princípios da aprendizagem criativa, uma vez que os participantes reunidos em equipes planejaram e criaram produções textuais de acordo com as dimensões do jogo, sorteadas em dados. Desta forma, os jogadores são incentivados a utilizarem suas habilidades de imaginação, reflexão, exploração, comunicação e colaboração para atingir os desafios propostos.

O percurso metodológico empregado neste trabalho passa por pesquisa bibliográfica, pesquisa ação e pelo uso do modelo MEEGA+ (Model for Evaluating Educational Games), que é usado para avaliação de jogos. Tal modelo foi construído tendo por base os seguintes elementos:

a) teorias da área de design instrucional e educação;

b) parte do modelo ARCS (Atenção, Relevância, Confiança e Satisfação);

c) taxonomia de Bloom;

d) parte do modelo de Kirkpatrick, o qual realiza a avaliação da experiência considerando a reação do aluno, além dos estudos das experiências do usuário ao utilizar jogos (SAVI, 2011).

A coleta de dados foi realizada por meio das produções textuais construídas durante a prática pedagógica com os estudantes e, principalmente, pelo questionário avaliativo respondido por eles. Esse questionário permitiu avaliar o jogo em três categorias: conhecimentos de RPG, percepção da aprendizagem, experiência do jogador e usabilidade. Alguns desses elementos são estabelecidos no modelo de avaliação do MEEGA+ (SAVI, 2011).

Visando a ampliar a compreensão dos pressupostos teóricos que fundamentaram o presente trabalho, a seção dois introduz alguns conceitos essenciais da aprendizagem criativa, bem como sua origem e seus quatro pilares. A seção três apresenta os pressupostos teóricos relacionados ao RPG, sua história e pesquisas correlatas com a educação. $O$ percurso metodológico composto por pesquisa bibliográfica e a pesquisa-ação conduzida encontram-se detalhados na seção quatro. Nesse capítulo, também constam as dimensões e regras do jogo The Legend of Creative Learning. Os resultados e discussões sobre a aplicação da prática pedagógica são descritos na seção cinco. Por fim, as conclusões são apresentadas na seção seis.

\section{Aprendizagem criativa: origem e seus 4Ps}

A aprendizagem criativa foi definida por Resnick (2007), inspirado nas teorias construcionistas de Papert (2008). Este último foi o primeiro pesquisador a recomendar que crianças usassem computadores para aprender os conceitos de matemática, propondo a primeira linguagem de programação direcionada a esse público - a linguagem LOGO. Na teoria construcionista, a aprendizagem ocorre sempre que o estudante a experimenta de forma criativa e colaborativa, de forma contextualizada à sua realidade (PAPERT, 2008). Isso significa que 
o aprendizado ocorre através de interações, manipulação de objetos concretos e experiências significativas ao contexto do aluno.

Desse modo, o que diferencia a aprendizagem criativa das demais estratégias e metodologias educacionais é o conceito de que os alunos possam não apenas criar coisas, mas expressar-se através de uma abordagem baseada em projetos, por exemplo: para se tornar fluente na escrita, não basta saber regras de ortografia e pontuação, pois "tornar-se fluente, seja na escrita ou na programação, ajuda a desenvolver seu pensamento, desenvolver sua voz e desenvolver sua identidade." (RESNICK, 2017, p. 6).

Resnick (2007) argumenta que "Para as crianças de hoje, nada é mais importante do que aprender a pensar criativamente - aprender a apresentar soluções inovadoras para as situações inesperadas que surgirão continuamente em suas vidas”. Ainda segundo Resnick (2014), os estudantes engajam-se na espiral da aprendizagem criativa (Figura 1) porque, com ela, eles podem imaginar, criar e concretizar seus projetos, brincar e experimentar suas criações, compartilhar e refletir sobre suas ideias. Tal engajamento permite imaginar novos projetos. Com esse ciclo estabelecido, os estudantes conseguem desenvolver seu pensamento reflexivo e criativo.

Figura 1 - Espiral da Aprendizagem Criativa

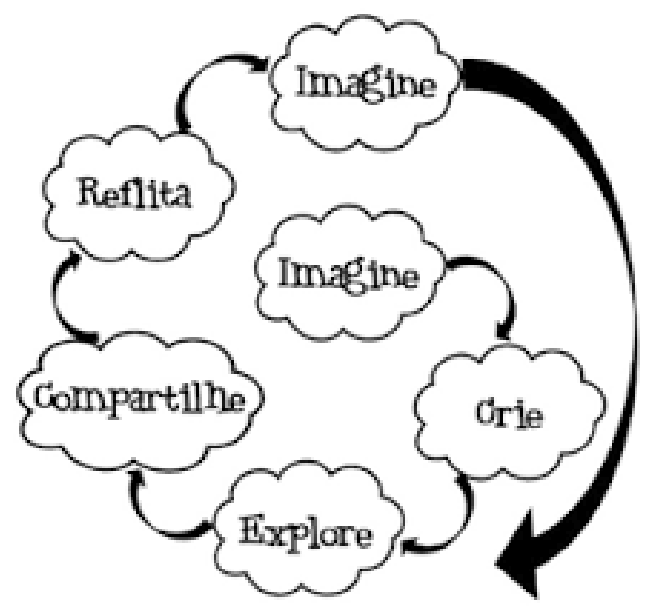

Fonte: Sobreira, Viveiro, Abreu (2020)

A aprendizagem criativa fundamenta-se em quatro pilares que a compõem chamados de os 4P's: Projeto, Paixão, Pares e Pensar brincando (RESNICK, 2017; RESNICK, 2007). "Projeto" consiste em planejar para colocar em prática as ideias. Ele deixa claro para o aluno que o planejamento e a organização são essenciais para o desenvolvimento de ideias e projetos. "Paixão" consiste na temática que vai mobilizar os esforços programados de forma significativa ao sujeito. Nesse caso, o ideal é dar autonomia ao estudante para que ele seja protagonista e tenha liberdade para construir e desenvolver seu projeto. "Pares" introduzem o valor social da colaboração, da cooperação e de que há construção de conhecimento através de trabalho em equipe, pois, ao contar com a colaboração de outras pessoas (parcerias), sugestões e feedbacks poderão aprimorar o projeto. Por fim, "Pensar brincando" permite aos estudantes atuarem de modo lúdico, sentindo-se livres para experimentar. Em tal contexto, ainda conforme argumenta Resnick (2014), aprender envolve realizar experimentações divertidas, que envolvem manipular materiais diferentes. 
Sobreira, Viveiro e Abreu (2018, p. 75) destacam que:

De acordo com a aprendizagem criativa, cabe analisar o uso das tecnologias na educação, com um olhar para promover um aprendizado significativo e criativo em que os alunos possam produzir conhecimentos com as tecnologias, desenvolvendo, assim, um letramento digital.

Nesse sentido, o jogo RPG possibilita articular diferentes tecnologias com o propósito de oportunizar que pessoas em diferentes locais possam se conectar no mesmo jogo online. Ao se jogar no formato presencial ou a distância, podem-se utilizar computadores, celulares, rede sociais, programas de compartilhamento de arquivos, ambientes virtuais de aprendizagem, software rolador de dados virtuais e aplicativo de construção colaborativa de textos.

As tecnologias digitais articulam-se com a aprendizagem criativa na medida em que proporcionam criação e desenvolvimento de projetos significativos ao contexto dos participantes através da ludicidade. Logo, essas ferramentas potencializam comunicação, engajamento, cooperação e colaboração (RESNICK, 2014).

\section{RPG: histórico e pesquisas}

Atualmente, existem várias pesquisas (PRENSKY, 2001; HUIZINGA, 1993; SAVI, 2011; MEIRA e BLIKSTEIN, 2020) sobre o estudo de jogos na educação, tanto no âmbito nacional como internacional. Segundo Huizinga (1993, p.7), "[...] encontramos o jogo na cultura, como um elemento dado existente antes da própria cultura, acompanhando-a e marcando-a desde as mais distantes origens até a fase de civilização em que agora nos encontramos". Desse modo, a potencialidade do fator lúdico contido em um jogo está inserida em diversas sociedades e foi utilizada ao longo da história humana, não sendo um fato recente.

Para Huizinga (1993), o jogo possui aspectos fundamentais e um deles é a representação de alguma coisa. No caso da criança, ela representa um personagem, algo diferente do que é real. "Finge ser um príncipe, um papai, uma bruxa malvada ou um tigre. A criança fica literalmente "transportada" de prazer, superando-se a si mesma a tal ponto que quase chega a acreditar que realmente é esta ou aquela coisa [...]" (HUIZINGA, 1993, p.17). Assim, a criança sente prazer ao imaginar e pode criar o seu próprio mundo sem perder totalmente o sentido da realidade.

Marc Prensky (2001) critica a forma como os professores americanos ensinam o conteúdo das aulas para seus alunos. "Em geografia [...] não há razão para uma geração que pode memorizar mais de 100 personagens do Pokémon com todas as suas características, história evolução não podem aprender os nomes, populações, capitais e relações entre todas as 181 nações no mundo." (PRENSKY, 2001, p. 6). Para o autor, o educador precisa ser criativo ao apresentar um assunto. Comenta que o discente aprende a jogar e ter interesse nos personagens dos jogos porque o jogo proporciona prazer ao ato de aprender. $\mathrm{O}$ fator de sucesso é apenas a forma como a aula é apresentada.

Os autores Huizinga e Prensky estão de acordo quando referenciam o prazer que a criança sente através da ludicidade e, assim, a possibilidade de potencializar sua aprendizagem. 
Prensky (2001) afirma que todas as disciplinas da escola podem ser apresentadas de forma lúdica desde que planejada criativamente para engajar o interesse do aluno. Inclusive, descreve comparações de como deixar outras disciplinas interessantes para os educandos.

No âmbito dos jogos, muitas possibilidades são encontradas, abrangendo desde recursos como cartas, dados, tabuleiros e até mesmo aparelhos digitais. Nesse sentido, os jogos de interpretações de papéis, os quais podem ser explorados com os recursos citados, oferecem aos professores oportunidade para abordar competências e habilidades orientadas pela Base Nacional Comum Curricular - BNCC (BRASIL, 2017).

O jogo Role Playing Game, também conhecido pela sigla americana RPG, adota como significado principal a interpretação de papéis. Jackson (1996) define o RPG: "Um role playing game é um jogo em que cada participante faz o papel de um personagem, tomando parte em uma aventura imaginária." (tradução nossa) (JACKSON, 1996, p.8). O RPG, na maioria das vezes, é jogado em grupo. Cada jogador interpreta o seu personagem e há um jogador que realiza o papel de mestre. O mestre é um narrador que conta a história a ser vivida pelos personagens e tem a função de avaliar os resultados das ações ou rolagens de dados efetuadas pelos demais jogadores. Jogos de RPG foram desenvolvidos nos Estados Unidos, na década de setenta por Gary Gygax e Dave A Tolkien, como O Hobbit e $O$ Senhor dos Anéis, onde os jogadores interpretam papéis de seus personagens nesses mundos fictícios.

Nos dias atuais, o D\&D está na sua quinta edição e, no ano de 2003, os autores da terceira versão descrevem a importância do produto para o desenvolvimento de jogos do gênero de RPG: "Este é o jogo de RPG Dungeons \& Dragons, o sistema que deu origem ao gênero e definiu os padrões para a interpretação da fantasia durante mais de 30 anos." (COOK; TWEET; WILLIAMS, 2003, p.4). No ano de 1986, foi lançado o jogo Generic Universal Role Playing System (GURPS) por Steve Jackson, conforme Barton e Stacks (2019), também nos Estados Unidos. O GURPS é um RPG com um sistema genérico para criação de ambientação e possui um sistema de regras próprio, diferenciando-se do sistema de seu concorrente D\&D no mercado de RPG.

Desde o lançamento dos primeiros jogos de RPG no Brasil (Aventuras fantásticas, Desafio dos bandeirantes, O Quilombo dos Palmares, Descobrimento do Brasil e Entradas e Bandeiras, entre outros) (RICON, 2012), percebeu-se o seu potencial para o ensino de história e geografia brasileira. Kastensmidt (2019) lança uma versão expandida do seu próprio livro de RPG, criado em 2017, intitulado "A Bandeira do Elefante e da Arara: Livro de Interpretação de Papéis", o qual usa um cenário ambientado no século XVI com criaturas do folclore brasileiro. A partir desse jogo, o autor argumenta que os professores podem planejar e utilizar o RPG como materiais paradidáticos em suas aulas, juntamente com os materiais didáticos, visando a proporcionar uma aula mais lúdica e a incentivar o engajamento através da interpretação de papéis, proporcionando maior criatividade.

O historiador Azevedo (2018) criou um jogo de RPG chamado "Aventuras Ancestrais" que utiliza cartas de baralhos com imagens das pinturas rupestres da época do sítio arqueológico Xique-Xique II. Nesse jogo, os jogadores interpretam caçadoras da sociedade que viveram no Brasil há 10 mil anos atrás em um cenário pré-histórico localizado no estado do Rio Grande do Norte. Ainda tratando de RPG e utilizando a mídia impressa, existe o RPG brasileiro gratuito com licença aberta, chamado Dominus (ARQUIVORPG, 2019). Esse contém regras simples, tabelas intuitivas, ambientação de cenários genéricos e pode ser jogado sem um narrador ou sozinho.

Ao analisar RPG em formato digital e considerando produções científicas internacionais ligadas à educação, podem-se citar alguns trabalhos relevantes: Mellado et al. (2018), Wu et 
al. (2016), Lee et al. (2014). Esses trabalhos testaram a potencialidade pedagógica desse jogo de interpretação de papéis no desenvolvimento de trabalho em equipe, resolução de problemas e estímulo à imaginação. Tais produções utilizam o RPG em conjunto com as tecnologias digitais para o ensino de mitos, estímulo à leitura, ensino de história e também na aprendizagem prática de desenvolvimento de software.

O RPG no formato digital citado em pesquisas nacionais encontra-se nos estudos de Cezar et al. (2019), Rosetti Junior et al. (2015), os quais descrevem que tais jogos auxiliam a construção de aprendizagens por meio da ludicidade, fator que fomenta o engajamento dos alunos quanto aos conteúdos desenvolvidos. Ademais, os autores mencionados utilizam o RPG para auxiliar na área da matemática, em disciplinas de cálculo de cursos de graduação, bem como nos conceitos da moeda para alunos de Ensino Fundamental.

No Brasil, são encontradas teses recentes como a de Dourado (2018) e a de Mesquita (2018) que pesquisaram a utilização do RPG dentro de ambientes virtuais de aprendizagem (AVA). Com foco no ensino, o primeiro pesquisador utilizou o AVA em relação à tecnologia móvel e o segundo investigou a história da independência do Brasil na Bahia.

Em buscas realizadas em periódicos, outro trabalho localizado compreende uma adaptação da obra "O Alienista", de Machado de Assis, para o formato de RPG. Nesse trabalho, os diversos cenários conduzem o "leitor-jogador" no jogo cujo roteiro segue a obra mencionada (MELO, TONELLO e BERTAGNOLLI, 2016). Outro trabalho considerado relevante e que usa critérios de avaliação semelhantes aos adotados pelo trabalho aqui proposto é o de Silva, Bez e Rigo (2018), que tem o objetivo de construir um jogo de RPG para o ensino de técnicas de informática. Esse jogo denominado My TechLife é um jogo de RPG direcionado para estudantes da área de informática, mais especificamente alunos de cursos técnicos.

Caballero et al. (2011), Santos (2011), Caballero (2007), Bittencourt e Giraffa (2003a) também avaliaram o impacto do jogo RPG digital dentro do AVA. Os jogos desenvolvidos ou estudados no AVA consideraram o papel do professor como mediador, e diversas disciplinas contidas na BNCC foram abordadas no jogo: matemática no estudo de geometria, história brasileira - como Guerra de Canudos - , conceitos de física, aprendizagem da escrita e diversos aspectos contidos em ciências naturais, entre outras disciplinas. Assim, o RPG pode otimizar e enriquecer o planejamento dos professores quanto às competências e habilidades norteadas pela BNCC.

Com base nesses trabalhos, pode-se afirmar que o uso do RPG como estratégia pedagógica em sala de aula tem despertado o interesse de pesquisadores. Alguns fatores têm sido apontados como os principais para a adoção desse gênero de jogo: interdisciplinaridade, colaboração, cooperação e criatividade.

\section{Percurso metodológico}

Conforme já mencionado previamente, a investigação iniciou-se por uma pesquisa bibliográfica (PRODANOV e FREITAS, 2013; GIL, 2008) que permitiu identificar gêneros de jogos e viabilizou que a escolha fosse por um RPG, devido à característica principal de possibilitar aos estudantes a interpretação de papéis. A seguir, foi realizado um estudo de trabalhos que utilizavam RPG, os temas abordados, sua aplicação pedagógica e as teorias de aprendizagem vinculadas. Analisaram-se em cada trabalho os recursos tecnológicos adotados e quais experiências criativas cada um deles permitia aos estudantes. Nesse estudo, foi localizado o formato Dominus, que possui uma estrutura simples que pode ser customizada e capacidade de sobrepor temas genéricos aos seus elementos organizacionais. 


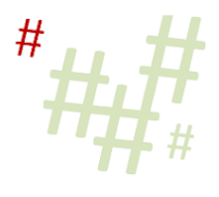

Ao concluir esses estudos teóricos, iniciou-se a elaboração de uma pesquisa-ação que seguiu os passos do ciclo estabelecido para esse tipo de pesquisa como definem Filippo, Roque e Pedrosa (2019): planejar, agir e refletir (Figura 2).

Figura 2: Ciclo com 3 etapas e respectivas atividades

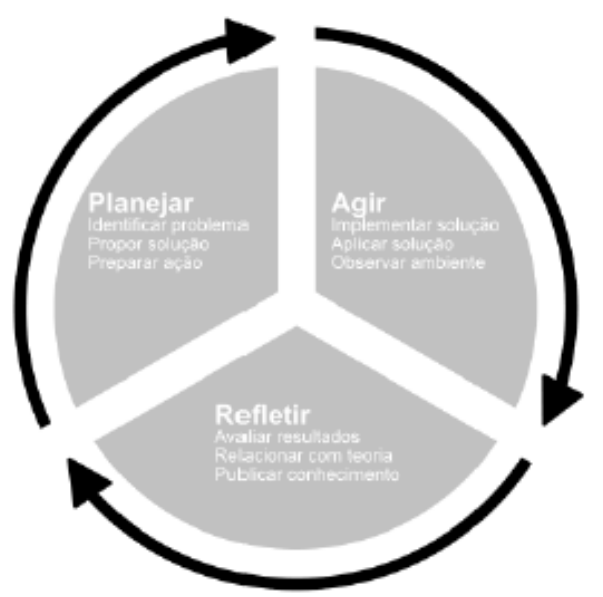

Fonte: Filippo; Roque; Pedrosa (2019).

Para o desenvolvimento do presente trabalho, o objeto da aprendizagem foi escolhido através da identificação do conjunto de participantes: 16 alunos do curso de Mestrado Profissional em Informática na Educação do Instituto Federal de Educação, Ciência e Tecnologia do Rio Grande do Sul - IFRS. Nesse curso, os alunos precisam estudar e compreender as diversas teorias da aprendizagem, conhecer os principais teóricos, analisar os principais pontos que conduzem à sua aplicação e determinar qual é o foco da teoria, se ela é construtivista, construcionista, significativa ou outra. Desse modo, nessa etapa foi identificado que o objetivo pedagógico seria o de criar uma abordagem pedagógica que permitisse o aprendizado das teorias de aprendizagem de forma lúdica e com criatividade. O lúdico conduziu as ações da pesquisa para a área de jogos, culminando com a escolha do gênero RPG. Já a criatividade direcionou as pesquisas para o uso da aprendizagem criativa, que oportunizou aos alunos trabalharem com a espiral criativa.

A proposição da solução foi realizada com a delimitação da intervenção pedagógica: os estudantes seriam divididos em grupos para jogar o The Legend of Creative Learning. Cada grupo assumiu o arquétipo de um teórico da área da educação (Jean Piaget, Lev Vygotsky, Frederic Skinner, David Ausubel, Seymour Papert e Howard Gardner) a fim de construir uma narrativa a respeito dos estudos e teorias de aprendizagem desses autores. Nessa fase foi selecionado o modelo MEEGA+ para auxiliar na avaliação, visto que ele estabelece um modelo simplificado que auxilia na coleta e na análise dos dados. Como instrumento de coleta de dados adotou-se questionário avaliativo, construído no Google Forms, o qual possui dez questões divididas em três dimensões: aprendizagem, usabilidade e experiência do jogador. A análise dos dados coletados foi realizada através de tabelas e gráficos que serão apresentados posteriormente na seção cinco.

Após concluir a primeira etapa do ciclo da pesquisa-ação, partiu-se para o segundo momento - o "Agir" - que iniciou com a sistematização do jogo RPG The Legend of Creative Learning. O mesmo foi elaborado pelos autores a partir do formato Dominus, o qual estabelece quatro dimensões: trama, personagens ou arquétipos, cenas e o banco de ideias, como ilustra a 
Figura 3. A primeira dimensão tem relação com a trama que deve levar em consideração os três itens "Algo aconteceu", "Você precisa" e "Senão". A segunda dimensão, "arquétipos", tem relação com alguns teóricos da área de educação, sendo esses os personagens que os grupos de alunos deveriam interpretar no jogo proposto. A dimensão "cenas" restringe-se a um conjunto de fatores (lugares, personagens e eventos). O "cenário" é onde a história do jogo pode se desenvolver. Já a dimensão "banco de ideias" serve como um recurso adicional para quando os alunos apresentam dificuldades de realizar a atividade, pois estão em um "cenário inconsistente".

Figura 3: The Legend of Creative Learning - tabelas e regras do jogo

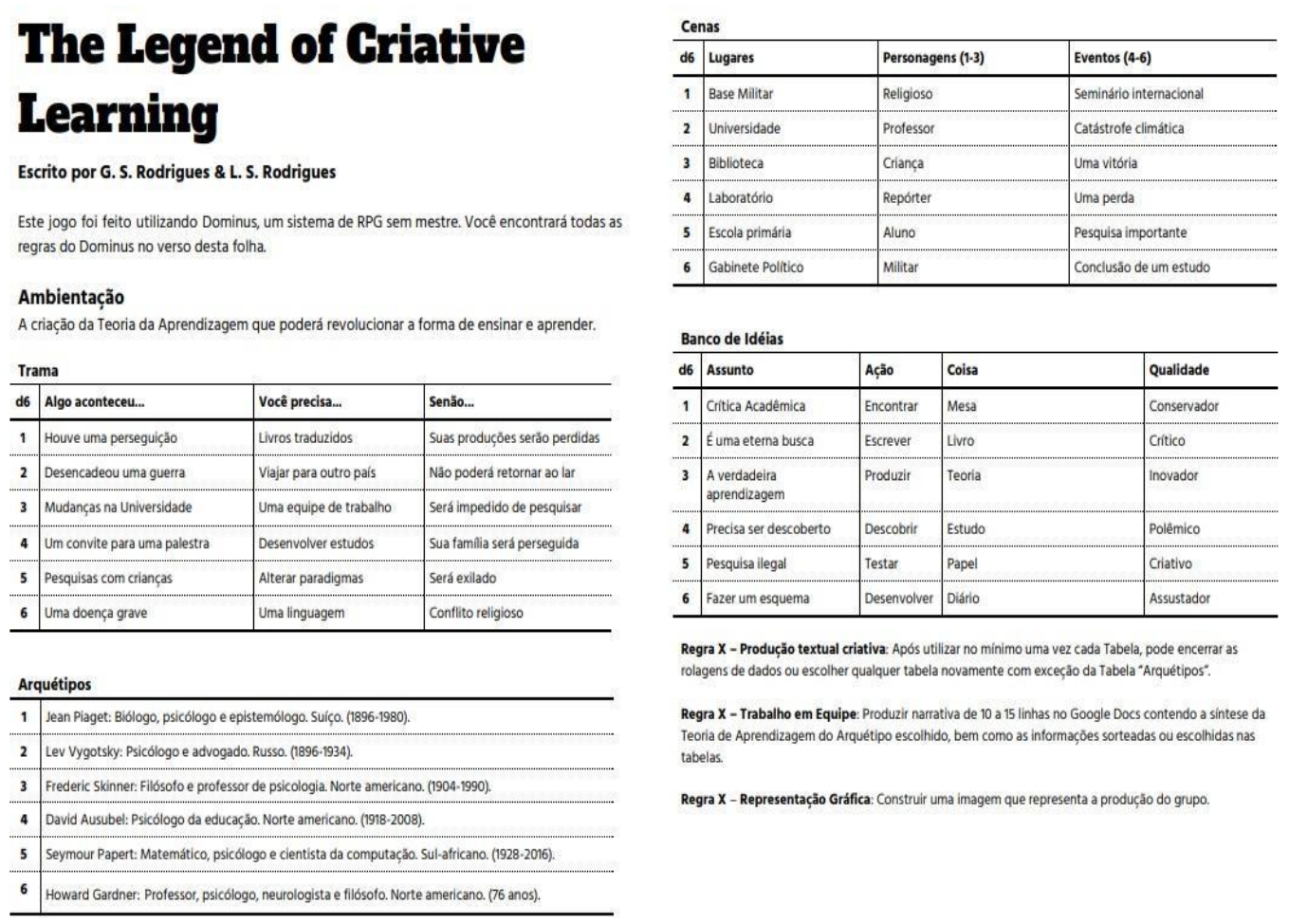

Fonte: Elaborado pelos autores (2019).

Para utilizar o jogo de RPG proposto, o professor, ou mestre de jogo (terminologia adotada em jogos do gênero de RPG), divide a turma em grupos pequenos e contextualiza a temática selecionada, nesse caso as Teorias da Aprendizagem. A seguir, o educador esclarece aos alunos que o jogo é baseado na interpretação de papéis e que eles deverão utilizar os conhecimentos prévios sobre o tema para elaborar um texto que aborde a relação com o teórico (arquétipo) designado ao seu grupo. É essencial que o professor deixe claro que a estratégia tem como foco a construção do seu aprendizado. Os grupos representam papéis dos arquétipos referentes a seis teóricos da área da educação a fim de construir de forma criativa uma narrativa a respeito de suas características e de suas teorias.

Em seguida, cada grupo utiliza a tabela chamada "Personagens/Arquétipos" contidas na "Regra 1: Preparação", onde será definido o personagem a ser interpretado e a teoria de aprendizagem que deve ser pesquisada e introduzida na narrativa. Um dado de seis faces é "rolado" para que haja um efeito de aleatoriedade para a definição do personagem central. Pela Regra 1 (Figura 4), os alunos poderiam escolher o arquétipo, mas como alguns grupos desejavam o mesmo arquétipo foi necessário rolar os dados para essa escolha. É importante ressaltar que todas as dimensões (Figura 3) estão atreladas com o número de lados do dado de 
seis faces. Assim, para a escolha do personagem, o grupo deveria "rolar" o dado. Se o número aleatório fosse o número "dois", o grupo iria escolher o personagem da linha dois e jogaria com o arquétipo "Lev Vygotsky: psicólogo e advogado russo (1896-1934)".

$\mathrm{Na}$ próxima etapa, deve-se utilizar novamente o rolador de dados para delimitar a dimensão "Trama", onde o rolador é utilizado três vezes: uma para indicar qual linha o grupo deverá usar na coluna "Algo aconteceu"; a segunda rolagem de dado indica a opção da coluna "Você precisa..."; e a terceira rolagem de dados indica uma das linhas da coluna "Senão". Se, por exemplo, os resultados das três rolagens para a "Trama" for três, três e cinco, os jogadores obtêm as seguintes informações: "Mudanças na Universidade"; "Uma equipe de trabalho"; "Será exilado".

No próximo passo, o rolador de dado é utilizado para definir a dimensão "Cena" que está contida na "Regra 2: História". O primeiro resultado do dado virtual define o lugar onde ocorre a trama; o segundo valor "rolado" define se o personagem encontra alguém (neste caso o resultado obtido no dado deve ser entre um e três), usando a coluna "Encontro", ou se ocorre algo (valor de quatro a seis no dado), relacionado com a coluna "Evento". Nesse momento, é importante mencionar a "Regra 3: Desafio", pois sempre que o personagem estabelecido para o grupo tentar fazer algo que possa dar errado, o grupo tem um desafio e é necessário rolar um dado. Se tirar quatro ou mais, o grupo consegue vencê-lo. Se houver algo nessa situação que dê vantagem no desafio, é necessário rolar dois dados e escolher o que contém o maior valor. Caso algo ofereça desvantagem ao grupo, então dois dados são rolados e deve-se escolher o menor resultado. A "Regra 4: Dilema" pode ser aplicada caso o personagem possua uma dúvida, cuja resposta não seja óbvia, e existam duas opções possíveis (sim ou não; esquerda ou direita; acontece A ou acontece B). Nesse caso, um dado é rolado. Se cair três ou menos, é a primeira opção, e se cair quatro ou mais é a segunda opção. O "Banco de Ideias contido" na Regra 5, deve ser utilizado se o grupo precisar elaborar melhor um Lugar, Personagem ou Evento. Role no "Banco de Ideias" e interprete o resultado de qualquer coluna de acordo com o Cenário ou, se o mestre permitir, apenas escolha a opção mais adequada.

Considerando-se a Figura 3, a "Regra X" orienta que o grupo, após ter jogado pelo menos uma vez cada tabela, deve construir uma produção textual em equipe no Google Docs contendo a síntese da teoria de aprendizagem do arquétipo escolhido, bem como as informações geradas através do efeito da aleatoriedade evidenciada pelo rolador de dados. O professor, aqui no papel do mestre do jogo, tem total liberdade para realizar as alterações que julgar necessárias.

Ao aplicar o jogo RPG The Legend of Creative Learning, com os 16 participantes, a partir do jogo ilustrado nas Figuras 3 e 4, observando o ambiente e as interações entre os estudantes, percebeu-se que os seguintes objetivos foram alcançados:

a) os estudantes conseguiram desenvolver em equipe estratégias de planejamento, construção, revisão e edição de texto, engajando-se no processo criativo da produção textual, utilizando-se da espiral criativa;

b) os alunos utilizaram softwares de edição de texto para produzir narrativa em colaboração com seus pares, explorando os recursos e multimídias disponíveis, observando a coerência dos fatos narrados com a época e a localidade em questão;

c) os estudantes conseguiram selecionar informações e dados, argumentos e outras referências em fontes confiáveis impressas e digitais, de forma a sintetizar os conceitos criados pelo personagem e contemplar a sustentação no que se refere às teorias educacionais de aprendizagens. 
Figura 4: The Legend of Creative Learning - regras do jogo

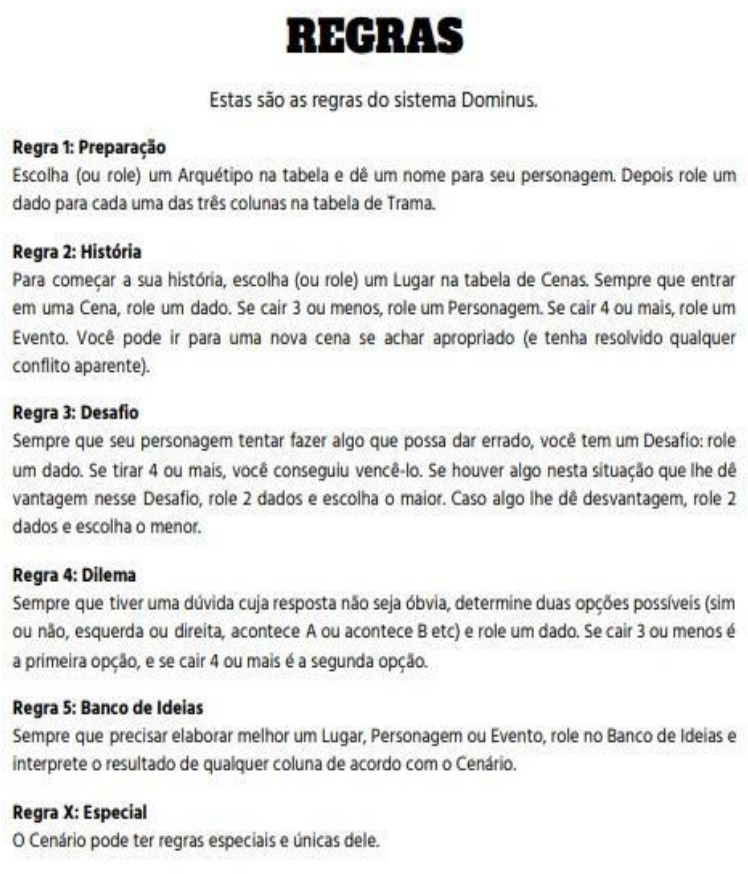

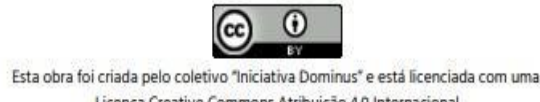

Licença Creative Commons Atribuiçăo 4.0 Internacional.
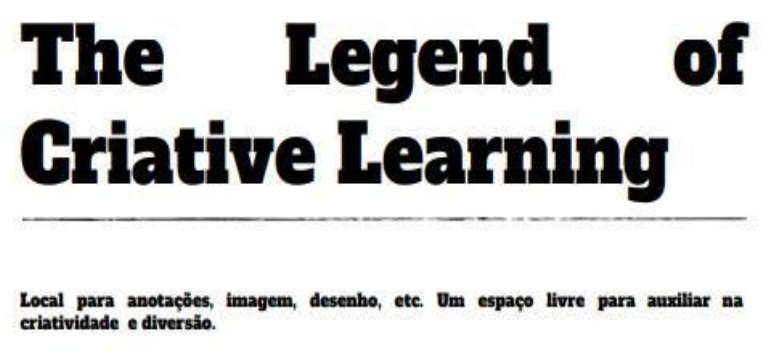

Fonte: Elaborado pelos autores, (2019).

Para alcançar os objetivos propostos, a turma foi dividida em grupos para jogar o RPG The Legend of Creative Learning. Os grupos representaram papéis dos arquétipos referentes aos autores Jean Piaget, Lev Vygotsky, Frederic Skinner, David Ausubel, Seymour Papert e Howard Gardner, a fim de construir narrativas a respeito de seus estudos e teorias de aprendizagem.

Várias TDICs foram utilizadas na prática pedagógica realizada. A recomendação do professor era de que as TDICs selecionadas permitissem explorar a teoria da aprendizagem criativa (RESNICK, 2014; RESNICK, 2017). Assim, foram utilizadas desde o Google Forms, Google Docs, WhatsApp, Moodle, entre outras, sendo que o dado utilizado era um dado virtual (Dice roller, rolador de dados virtual ${ }^{1}$ ). Com a conclusão da prática, os estudantes foram convidados a responder um questionário com 10 perguntas, onde avaliaram a atividade proposta e o jogo. A próxima seção irá apresentar alguns resultados obtidos com a coleta de dados e algumas discussões sobre a pesquisa desenvolvida.

\footnotetext{
${ }^{1}$ Disponível em: https://www.google.com/search?q=dice+roller.
} 


\section{Resultados: reflexões e discussões}

A prática pedagógica proposta foi avaliada considerando-se os conhecimentos prévios de RPG, o uso de jogos digitais e não digitais como ferramenta de aprendizagem, os reflexos da proposta na aprendizagem e aspectos vinculados à experiência do jogador, visto que a prática estava fundamentada no uso de jogos em sala de aula. Assim, a análise dos resultados é realizada por meio da comparação entre os grupos de perguntas que faziam parte do questionário.

A primeira pergunta realizada aos estudantes dizia respeito ao conhecimento dos mesmos sobre o gênero de RPG. Nesse levantamento, metade dos participantes já havia jogado esse tipo de jogo previamente e a outra metade nunca antes de participarem da prática pedagógica. Dessa forma, presume-se que a proposta era inédita para esses últimos.

Gráfico 1: Qual o seu contato com Role Playing Game (RPG) antes de sua aplicação em sala de aula?

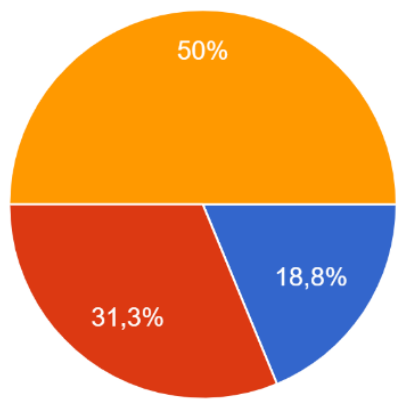

Fonte: Elaborado pelos autores, (2019).

Outro questionamento realizado foi "Você acredita que o RPG tem potencial educacional?". Em resposta à pergunta, todos os participantes acreditam que o RPG possui potencial para ser utilizado no processo de ensino-aprendizagem. Através da experiência proporcionada aos partícipes pelo jogo de RPG The Legend of Creative Learning, é possível afirmar que essa proposta aumentou o leque de estratégias pedagógicas de formato criativo que os professores podem utilizar em suas aulas.

As respostas desse questionamento estão alinhadas com as pesquisas realizadas por (CEZAR et al., 2019; MELLADO et al., 2018; WU et al., 2016), que apontam que há um grande potencial pedagógico do jogo RPG na educação. A seguir, foi solicitado que os participantes comentassem sua resposta. Os alunos afirmaram que é possível a utilização do jogo apresentado com sucesso na sala de aula, desde que o docente insira em seu planejamento a utilização do mesmo para contextualizá-lo com os conteúdos programáticos. Outros participantes mencionaram que, além da produção textual estimulada pelo jogo criado pelos autores da pesquisa, outros conteúdos vinculados a BNCC podem ser aplicados para manter o engajamento da turma nas aulas e estimular a criatividade de alunos e professores.

Quando questionados sobre a possibilidade de utilizar a prática pedagógica proposta, 93,8\% dos partícipes responderam que a utilizariam como estratégia em sala de aula e menos de $6 \%$ não utilizaria. É importante salientar que a única resposta negativa deve-se ao fato de o respondente não ter visto relação do jogo RPG com a sua área de trabalho: "Acredito que o 
RPG seja pouco relacionado a minha área." Isso deixa claro que é necessário realizar uma maior contextualização da prática e explicitar outros contextos em que ela pode ser aplicada.

Gráfico 2: Você utilizaria a prática pedagógica utilizada em sala de aula?

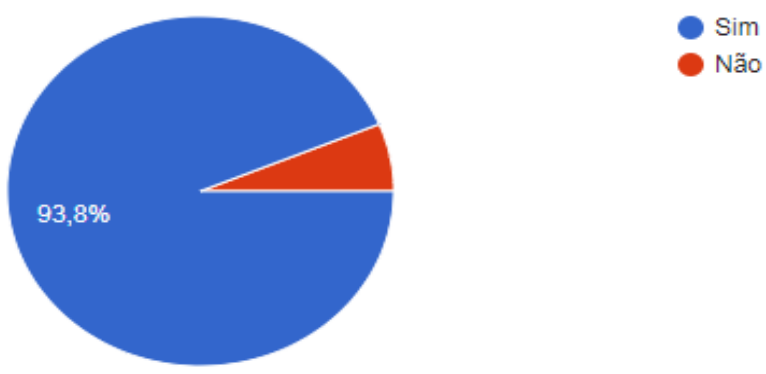

Fonte: Elaborado pelos autores, (2019).

Foi solicitado que comentassem os motivos que os levariam a utilizar a prática pedagógica em sala de aula. Nesse sentido, os participantes responderam que aplicariam o jogo The Legend of Creative Learning em suas aulas, como demonstram os relatos dos participantes P1, P3 e P6:

P1: "Utilizarei por considerar que é relevante para o aprendizado, utilizando aspectos lúdicos que prendem a atenção."

P3: “Achei muito interessante essa abordagem. É preciso reinventar a sala de aula para que os alunos consigam se concentrar e ter uma aprendizagem efetiva, e isso o jogo proporcionou."

P6: "Me pareceu ser uma metodologia que abre inúmeras possibilidades, inclusive para trabalhos interdisciplinares. Com certeza eu utilizaria, mas teria que me apropriar melhor de conceitos, ..."

Dessa forma, entende-se que as aulas têm maiores chances de sucesso quando utilizam o lúdico. Também foi mencionada a importância que esse jogo tem ao propor o trabalho em grupo e, ao mesmo tempo, proporcionar o engajamento e a atenção através da interpretação de um personagem que, de acordo com o citado pelo participante P6: "Utilizaria devido a seu potencial de desenvolvimento criativo, colaborativo, lúdico e de atualização frente aos interesses emergentes".

No modelo MEEGA+ a "Experiência do jogador" é avaliada por um conjunto de 30 questões relativas à usabilidade, relevância, atenção focada, diversão, interação social, desafio, satisfação e percepção de aprendizagem. Essas questões têm o propósito de coletar informações relativas à experiência de cada jogador.

Sobre a aprendizagem criativa, os participantes foram questionados da seguinte forma: “O jogo me proporcionou uma aprendizagem criativa?”. No caso dessa questão, $50,0 \%$ dos participantes concordam que o jogo propiciou esse tipo de aprendizagem e 31,2\% dos alunos responderam que concordam totalmente que o jogo aplicado na prática proporcionou aprendizagem criativa. Dessa forma, pode se concluir que $81,2 \%$ dos partícipes responderam positivamente ao questionamento, corroborando o que afirmam Resnick (2007) e Prensky (2001) quando afirmam que estratégias lúdicas e o uso de jogos podem ser usados para alcançar a aprendizagem criativa. 
Figura 5: Experiência do Jogador - Percepção da Aprendizagem

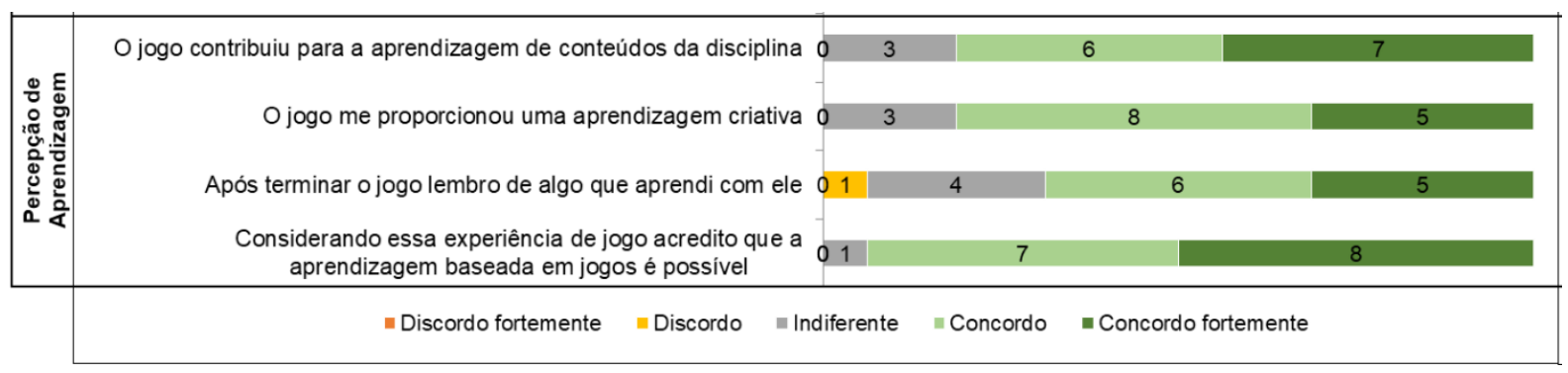

Fonte: Elaborado pelos autores, (2019).

A Figura 5 ainda ilustra que 81,2\% dos participantes apontam que há uma contribuição do jogo de RPG para a aprendizagem de conteúdos da disciplina na qual a prática pedagógica foi realizada, demonstrando o potencial pedagógico do jogo The Legend of Creative Learning. Nesse aspecto, os estudos de Jean Piaget (1964) contribuem com a análise dos resultados ao afirmar que, para a construção de aprendizagens, é necessário que haja interações com a realidade e que as aplicações pedagógicas ou didáticas auxiliem no fortalecimento das estruturas cognitivas.

A partir da Figura 6, algumas observações podem ser obtidas. Com relação à confiança, percebe-se que a maioria dos estudantes identificou que a organização do jogo beneficiaria a aprendizagem. Nesse caso, percebe-se o quanto foi essencial o planejamento da atividade, pois os conceitos teóricos estudados foram aplicados, como estabelece a pesquisa-ação (FILIPPO, ROQUE e PEDROSA, 2019), e ocorreram trocas de ideias entre os pesquisadores antes da prática pedagógica ser aplicada em sala de aula. Pode-se afirmar que a parte da espiral de aprendizagem criativa foi usada pelos pesquisadores para elaborar a abordagem pedagógica apresentada. Com relação à "Interação Social", "Relevância" e "Diversão", os participantes avaliaram de forma positiva o uso de jogos e estratégias lúdicas em sala de aula, inclusive como relata o participante P7: "Vejo grande potencial na aplicação de jogos para o aprendizado, desde que tenha boa adaptação dos temas vistos em aula.".

Os componentes "Satisfação" e "Atenção focada" foram os que apresentaram os resultados mais negativos, o que revela quais aspectos devem ser evoluídos no jogo. Acreditase que isso ocorreu porque o jogo foi conduzido em computadores e não apresenta desafios progressivos aos estudantes, o que pode ter reduzido a atenção e o engajamento. 
Figura 6: Modelo MEEGA+ e a Experiência do Jogador

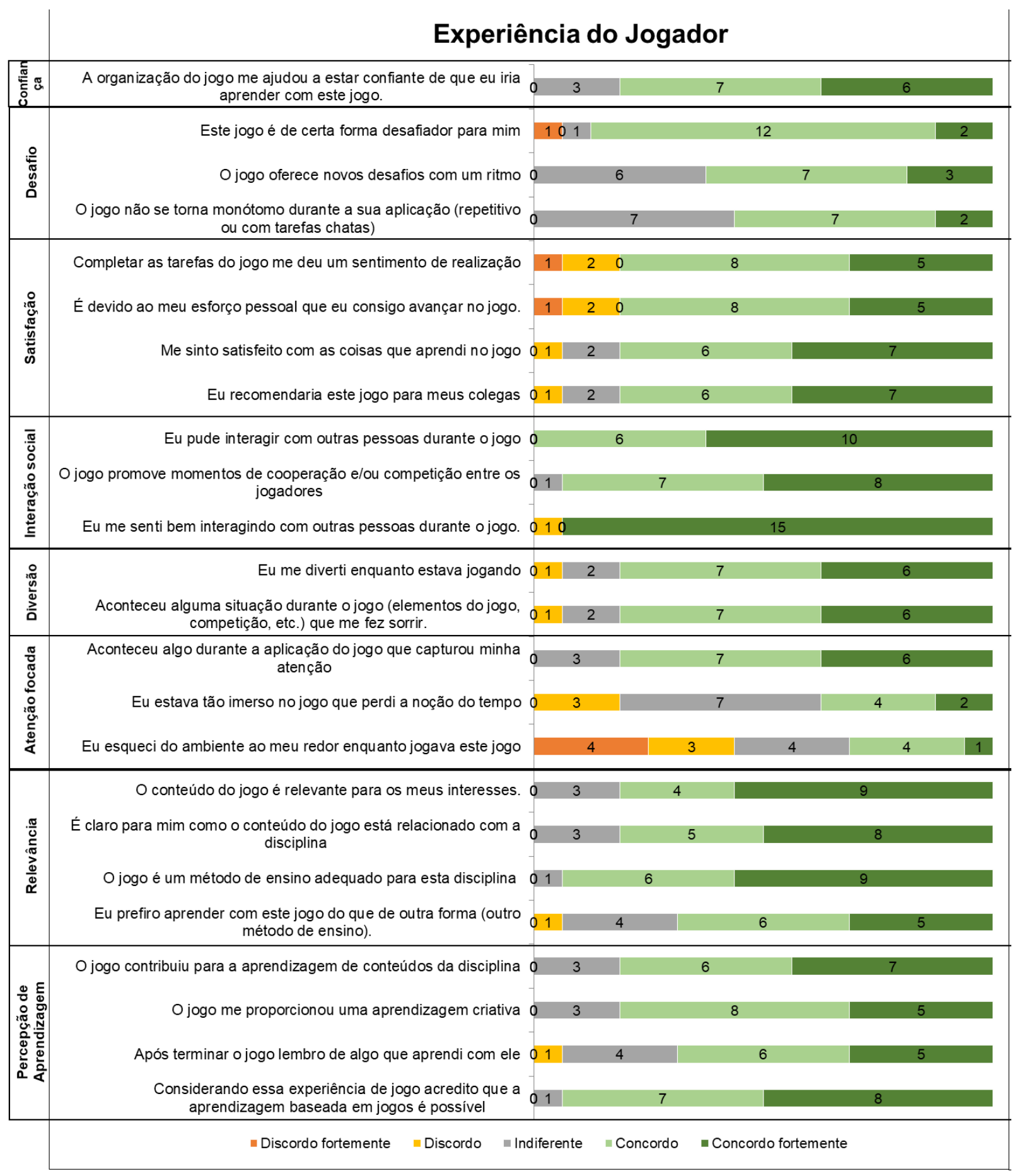

Fonte: Elaborado pelos autores, (2019).

O projeto visual do jogo foi construído utilizando-se o formato Dominus, logo, não foi possível incluir muitos elementos gráficos/visuais. Mesmo assim, o jogo proposto foi bem avaliado acerca de sua estética. Embora 50\% dos participantes não tivessem jogado jogos do gênero RPG, a grande maioria dos participantes achou o jogo fácil e apontou que outros aprenderiam a jogá-lo rapidamente. A facilidade em compreender as regras e os elementos que 
fazem parte do jogo também foram indicados como facilitadores para a adoção do jogo em sala de aula (Figura 7).

Figura 7: Modelo MEEGA+ e a Usabilidade

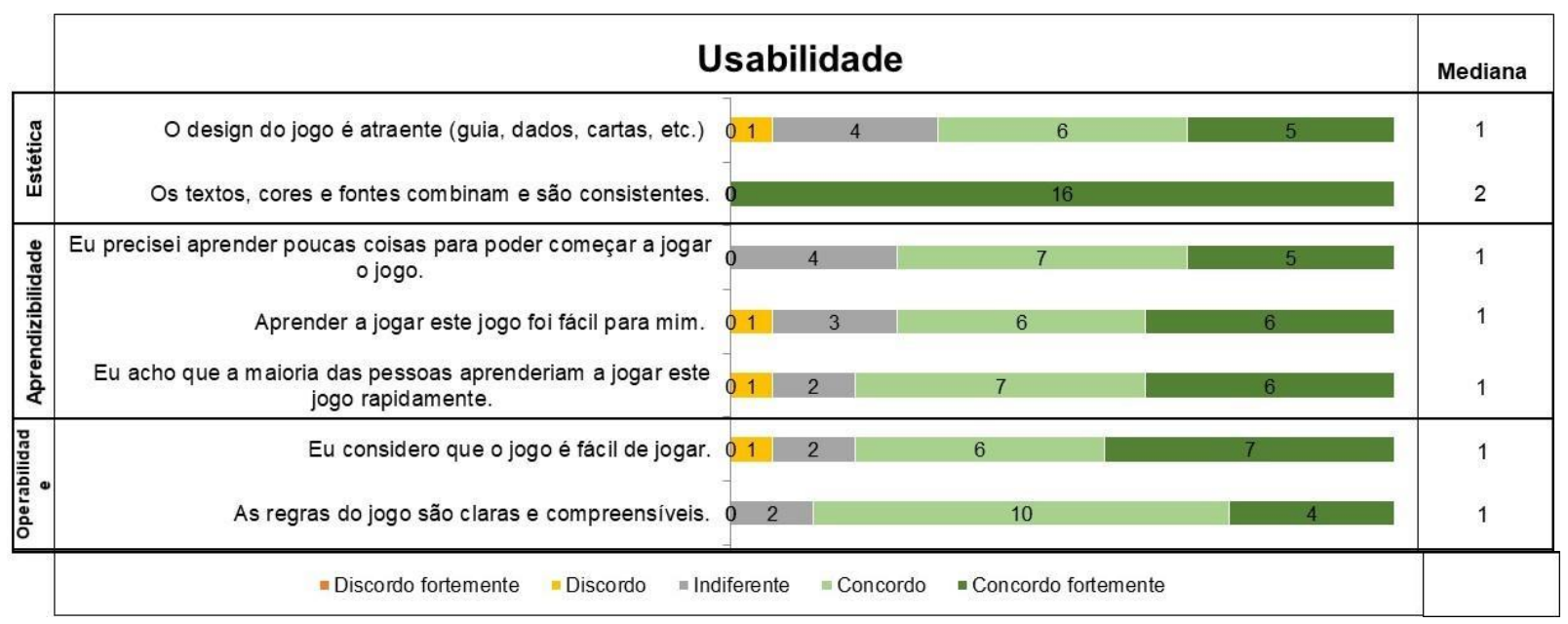

Fonte: Elaborado pelos autores, (2019).

Considerando a seção de comentários adicionais do questionário, algumas observações foram julgadas pertinentes ao contexto deste artigo: P8: "Vejo um enorme potencial para aplicação no ensino médio." P6: "Me pareceu ser uma metodologia que abre inúmeras possibilidades, inclusive para trabalhos interdisciplinares.”. Com essas afirmações, percebe-se que alguns estudos devem ser conduzidos de modo a integrar disciplinas diferentes no contexto da Educação Básica, para avaliar a aplicabilidade do jogo com esse nível de ensino.

\section{Conclusões}

Ao longo do processo de investigação e escrita do presente artigo, conclui-se que o objetivo principal foi atingido através da confecção do jogo The Legend of Creative Learning. Este dado é confirmado pela amostra de $93,8 \%$ dos participantes que pretendem utilizar a metodologia apresentada no seu planejamento educacional.

Quanto ao uso de uma metodologia de pesquisa sistematizada em fases, a mesma possibilitou planejar, executar e refletir sobre a prática pedagógica como um todo. Além disso, ao utilizar o modelo MEEGA+, a coleta e a análise dos dados ficaram simplificadas, pois ele delimita um percurso quali-quantitativo que permite identificar o que funcionou e o que deve ser aprimorado no jogo.

A proposta pedagógica desenvolvida pode ser replicada em outros contextos educacionais, uma vez que os recursos necessários para jogar são de fácil acesso: um dado de 6 faces, caneta ou lápis e o mesmo pode ser impresso em apenas uma folha de tamanho A4 frente verso. Também deve ser ressaltada a facilidade de adaptar um jogo com propósito recreativo em um jogo com objetivo de aprendizagem criativa, o qual tem o potencial de abordar competências e habilidades orientadas pela BNCC.

Ao finalizar esta produção, entende-se como possibilidade para futuras pesquisas a aplicação do jogo com alunos da Educação Básica, a fim de analisar engajamento, potencialidades e dificuldades com o uso do jogo. Recomenda-se também o desenvolvimento 
do jogo The Legend of Creative Learning em formato digital, pois isso facilitaria o acesso ao jogo e atenderia as necessidades do público que prefere esse formato.

\section{Referências}

ARQUIVORPG. Dominus: o RPG Sem mestre para jogos rápidos. 2019. Disponível em: https://arquivorpg.com.br/dominus/. Acesso em: 20 set. 2019.

AZEVEDO, Diego. Aventuras Ancestrais. Rio de Janeiro: Editora Game Maker, 2018. Disponível em: https://aventurasancestrais.wordpress.com/2018/03/14/motivos-para-teraventuras-ancestrais/. Acesso em: 16 dez. 2019.

BARTON, M.; STACKS, S. Dungeons and Desktops: The History of Computer RolePlaying Games. 2. ed. New York: CRC Press, 2019.

BITTENCOURT, J. R.; GIRAFFA, L. M. Modelando Ambientes de Aprendizagem Virtuais utilizando Role-Playing Games. XIV Simpósio Brasileiro de informática na educação. Rio de Janeiro: SBC, 2003a. Disponível em:

https://www.brie.org/pub/index.php/sbie/article/view/299. Acesso em: 13 nov. 2019.

BITTENCOURT, J. R.; GIRAFFA, L. M. A Utilização dos Role-Playing Games Digitais no Processo de Ensino-Aprendizagem. Programa de Pós-graduação em Ciências da Computação. PPGCC/PUCRS, p. 62, 2003b. (Relatório Técnico). Disponível em: http://www.pucrs.br/facin-prov/wp-content/uploads/sites/19/2016/03/tr031.pdf. Acesso em: 05 nov. 2019.

CABALLERO, S. da S. X.; MATTA, A. E. R.; SOUZA, A. L.; NEIME, M.; MONTALVAO, V.; VIDAL, E.; SANTANA, E. RPG By Moodle. 1. ed. Salvador: Universidade do Estado da Bahia, 2011.

CABALLERO, S. da S. X. O RPG digital na mediação da aprendizagem da escrita. Dissertação (Mestrado em Educação) - Programa de Pós-Graduação em Educação e Contemporaneidade, Universidade do Estado da Bahia, Salvador, p.207. 2007. Disponível em: http://www.cdi.uneb.br/site/wpcontent/uploads/2016/01/sueli_da_silva_xavier_cabalero.pdf. Acesso em: 01 dez. 2019.

CEZAR, V.; GARCIA, P.; BOTELHO, V.; MILETTO, E. Towards an RPG Game to Teach Calculus. IEEE 19th International Conference on Advanced Learning Technologies (ICALT). 2019. Disponível em:

https://ieeexplore.ieee.org/search/searchresult.jsp?newsearch=true\&queryText=doi:10.1109\% 2Ficalt.2019.00037. Acesso em: 15 nov. 2019.

COOK, M.; TWEET, J.; WILlIAMS, S. Dungeons \& Dragons Player's Handbook: Core Rulebook. I V.3.5. [s.1.]: Wizards of the Coast, 2003.

DARLINGTON, Steve. A history of role-playing. USA, 1999. Disponível em: http://ptgptb.org/0001/history1.html. Acesso em: 20 nov. 2019. 
DORMANS, Joris. On the role of the die: a brief ludologic study of pen-and-paper roleplaying games and their rules. Game Studies, the international journal of computer game research. v. 6, n. 1, Dec. 2006. Disponível em: http://gamestudies.org/0601/articles/dormans. Acesso em: 01 nov. 2019.

DOURADO, M. M. de S. RPGAD Móvel: Uma solução educacional recursiva usando princípios socioconstrutivistas. (Doutorado Multi-institucional e Multidisciplinar em Difusão do Conhecimento - DMMDC) - Programa de Pós-Graduação em Difusão do Conhecimento, Universidade Federal da Bahia, Salvador, p. 225. 2018.

FILIPPO, Denise; ROQUE, Gianna; PEDROSA, Stella. Pesquisa-ação: possibilidades para a Informática Educativa. In: PIMENTEL, Mariano; SANTOS, Ednéa Oliveira dos; PIMENTEL, Edson. (Org.) Metodologia de Pesquisa em Informática na Educação: Abordagem Qualitativa de Pesquisa. Porto Alegre: SBC, 2019. (Série Metodologia de Pesquisa em Informática na Educação, v. 3) Disponível em: http://metodologia.ceiebr.org/livro-3/. Acesso em: 18 set. 2019.

GIL, A. C. Métodos e técnicas de pesquisa social. 6. ed. São Paulo: Atlas, 2008.

HUIZINGA, Johan. Homo Ludens: o jogo como elemento da cultura. São Paulo: Perspectiva, 1993.

JACKSON, Steve. GURPS Basic Set. Generic Universal Role Playing System. 3. ed. [s.1.]: Steve Jackson Games, 1996.

KASTENSMIDT, Christopher. A Bandeira do Elefante e da Arara: Livro de Interpretação de Papéis. 1. ed. São Paulo: Devir, 2019.

KELLER, J. M. Motivational Design for Learning and Performance: The ARCS Model Approach. Springer, 2009.

LEE, G. H., TALIB, A. Z., ZAINON, W. M. N. W., LIM, C. K. Learning History Using Role-Playing Game (RPG) on Mobile Platform. In: Jeong H., S. Obaidat M., Yen N., Park J. (eds) Advances in Computer Science and its Applications. Lecture Notes in Electrical Engineering, v. 279. Springer, Berlin, Heidelberg. 2014. Disponível em:

https://link.springer.com/chapter/10.1007/978-3-642-41674-3_104. Acesso em: 15 nov. 2019.

MEIRA, L; BLIKSTEIN, P. Ludicidade, Jogos Digitais e Gamificação na Aprendizagem. Porto Alegre: Penso, 2020.

MELLADO, R.; MELGAREJO, B.; VELASQUEZ, C.; CUBILLOS, C.; RONCAGLIOLO, S.; GONZALEZ, N. Video game tool for teaching myths and legends to school basic students. In: International Conference of the Chilean Computer Science Society (SCCC), Santiago, Chile, 2018, p. 1-8. Disponível em:

http://ieeexplore.ieee.org/stamp/stamp.jsp?tp=\&arnumber=8705258\&isnumber $=8705150$. Acesso em: 01 nov. 2019.

MELO, C. V.; TONELlO, G. H.; BERTAGNOLLI, S. C. Do livro ao RPG: Conexões entre arte literária e jogos digitais em educação. \# Tear: Revista de Educação Ciência e 
Tecnologia. Canoas, v.5, n.2, p. 1-23, 2016. Disponível em: https://periodicos.ifrs.edu.br/index.php/tear/article/view/2020. Acesso em:12 mar. 2020.

MESQUITA, J. P. Ensino de história e jogos digitais: Experiência com RPGAD para o ensino da independência do Brasil na Bahia. Tese (Doutorado Educação e Contemporaneidade) - Programa de Pós-Graduação em Educação e Contemporaneidade, Universidade do Estado da Bahia, Salvador, p. 206. 2018.

\section{MINISTÉRIO DA EDUCAÇÃO (MEC). Base Nacional Comum Curricular. 2017.} Disponível em: http://basenacionalcomum.mec.gov.br/wp-content/uploads/2018/02/bncc20dez-site.pdf. Acesso em: 11 set. 2019.

MURCIA, J. A. M. Aprendizagem através do jogo. Porto Alegre: Artmed, 2005.

NOVAK, J. Desenvolvimento de games. 2. ed. São Paulo: Cengage Learning, 2010.

PAPERT, S. Instrucionismo versus construcionismo. In: _. A máquina das crianças: repensando a escola na era da informática. Porto Alegre: Penso, 2008.

PETERSON, Jon. Playing at the world: A history of simulating wars, people and fantastic adventures, from chess to role-playing games. San Diego: Unreason Press, 2012.

PIAGET, Jean. Part I: Cognitive development in children: Piaget development and learning. Journal of research in science teaching, v. 2, n. 3, p. 176-186, 1964. Disponível em: https://scholar.google.com.br/scholar?hl=pt-BR\&as_sdt=0\%2C5\&q=piaget\&btnG=. Acesso em: 15 dez. 2019.

PRENSKY, Marc. Digital Natives, Digital Immigrants Part 1. On the Horizon. v.9. 1-6.pg n. 5, Out, 2001. Disponível em: https://www.marcprensky.com/writing/Prensky\%20\%20Digital\%20Natives,\%20Digita1\%20Immigrants\%20-\%20Part1.pdf . Acesso em: 04 dez. 2019.

PRODANOV, Cleber Cristiano; FREITAS, Ernani Cesar de. Metodologia do trabalho científico: métodos e técnicas da pesquisa e do trabalho acadêmico. 2. ed. Novo Hamburgo: Feevale, 2013.

RESNICK, Mitchel . Lifelong Kindergarten: Cultivating Creativity Through Projects, Passion, Peers, and Play. MIT Press, 2017. Disponível em:

https://learn.media.mit.edu/lcl/resources/readings/chapter1-excerpt.pt.pdf?pdf=ch1-pt. Acesso em: 28 out. 2019.

RESNICK, Mitchel. Give P's a chance: projects, peers, passion, play. Constructionism and Creativity conference. Opening keynote. Vienna, 2014. Disponível em:

https://web.media.mit.edu/ mres/papers/constructionism-2014.pdf. Acesso em: 28 out. 2019.

RESNICK, Mitchel. All I really need to know (about creative thinking) I learned (by studying how children learn) in kindergarten. Proceedings conference on Creativity \& cognition, p.1-6, June 13-15. Washington, DC, USA, 2007. Disponível em: 
https://scholar.google.com/citations?user=KKq5SN4AAAAJ\&hl=en. Acesso em: 15 dez. 2019.

RICON, Luiz E. Desafio dos Bandeirantes: 20 anos. REDERPG. 2012. Disponível em: https://www.rederpg.com.br/2012/12/13/desafio-dos-bandeirantes-20-anos/. Acesso: em 12 dez. 2019.

ROSETTI JUNIOR, H.; AMARAL, G. P., SCHIMIGUEL, J., MARTINS, C. A.; ARAÚJO JUNIOR, C. F. O jogo na educação matemática: desenvolvimento de um RPG para trabalhar o conceito de moeda no ensino fundamental. In: HOLOS, ano 31, v. 8., 2015. Disponível em: http://www2.ifrn.edu.br/ojs/index.php/HOLOS/article/view/3607/1315. Acesso em: 07 nov. 2019.

SANTOS, C. C. D. RPG GEO MOODLE: Modelagem dos dados de múltiplas faces. Dissertação (Mestrado em Modelagem computacional e tecnologia industrial) - Senai/ Cimatec, Salvador, p. 118. 2011. Disponível em:

http://portais.fieb.org.br/portal_faculdades/images/portal/NRM/DissertacoesMCTI/dis sertacao_carmen.pdf. Acesso em: 03 out. 2019.

SAVI, Rafael. Avaliação de jogos voltados para a disseminação de conhecimentos. Tese (Doutorado) - Universidade Federal de Santa Catarina, Florianópolis, p. 238. 2011.

SCHUYTEMA, Paul. Design de games: uma abordagem prática. São Paulo: Cengage Learning, 2008.

SILVA, D. P.; BEZ, M. R.; RIGO, S. J. My TechLife: Desenvolvimento e Validação de um Jogo para o Ensino Técnico em Informática. RENOTE, v. 16, n. 1, jul., 2018. Disponível em: https://seer.ufrgs.br/renote/article/view/85878/49286. Acesso em: 12 mar. 2020.

SOBREIRA, E. S. R.; VIVEIRO, A. A.; ABREU, J. V. V. Cultura Maker e Jogos Digitais. In: Ludicidade, jogos digitais e gamificação na aprendizagem. In: MEIRA, L.;

BLIKSTEIN, P. (Org.) Ludicidade, Jogos Digitais e Gamificação na Aprendizagem. Porto Alegre: Penso, 2020. (Coleção Tecnologia e Inovação na Educação Brasileira v. 3).

SOBREIRA, E. S. R.; VIVEIRO, A. A.; ABREU, J. V. V. Aprendizagem criativa na construção de jogos digitais: uma proposta educativa no ensino de ciências para crianças. Tecné Episteme y Didaxis TED, n. 44, p. 71-88, 2018.

WU, W.-H., YAN, W.-C., KAO, H.-Y., WANG, W.-Y., WU, Y.-C. J. Integration of RPG use and ELC foundation to examine students' learning for practice. Computers in Human

Behavior, n. 55, p. 1179-1184. 2016. Disponível em: https://www.sciencedirect.com/science/article/pii/S0747563214005469. Acesso em: 09 nov. 2019.

Recebido em março de 2020.

Aprovado em maio de 2020. 